\title{
Effects of Soil on the Seismic Design of Long Span Steel Frames Using Con- temporary Building Codes
}

\author{
Muhammad Tayyab Naqash*, Qazi Umar Farooq \\ ${ }^{1}$ Department of Civil Engineering, Faculty of Engineering, Islamic University Madinah, Prince Naif Ibn Abdulaziz, Al \\ Jamiah, Madinah, KSA \\ ${ }^{*}$ Corresponding author: engr.tayyabnaqash@gmail.com
}

Abstract

Seismic excitations and other lateral dynamic distress cause the structure's foundation to interact with the superstructure's response. Consequently, the surplus stress distribution takes place. This disturbance in the lateral stiffness of the system can cause un-satisfaction with the adopted code provisions. In the above scenario, soil structure interaction of the Moment Resisting Frames (MRFs) becomes very crucial. This article deals with soil stiffness on the long-span MRFs designed with two modern building codes, namely Saudi Building Code (based on American Standards) and Eurocodes. High and medium ductility with parameter and spatial frame configurations are considered in this study. Each frame is analysed considering the foundation stiffness, calculated based on FEMA recommendations. Hence, a total of 18 cases are examined, conducting a modal response spectrum analysis. The period, top displacements, reactions, and damageability criterion for the analyzed frames are compared. It is shown that the consideration of SSI (Soil Structure Interaction) is paramount for frames with such spans, especially when subjected to high seismic forces.

Keywords-Seismic codes, soil structure interaction, drift criteria, fundamental period, Saudi Building Code, Eurocodes, moment resisting frames

\section{Introduction}

L ATERAL forces induced from ground motion and wind are the primary reasons for the building vibrations. The mechanism that influences the mid to high-rise structure's vibration characteristics is the dynamic Soil-Structure Interaction (SSI), governed by the soil mechanical behaviour. When a structure is subjected to seismic activity, it interacts with the foundation and the soil and changes with the ground motion. This phenomenon is called kinematic interaction and becomes essential when the foundation's stiffness is different from that of the ground. Kinematic interaction substitutes and increases with the size of the foundation. Rigid steel frames have a high fundamental period due to their flexibility. The situation becomes worst in long spans when flexural governs the design. Steel gives the possibility of a perimeter and spatial framing system. When the perimeter framing

ISSN: 2523-0379 (Online), ISSN: 1605-8607 (Print)

DOI: 10.52584/QRJ.1802.01

This is an open access article published by Quaid-e-Awam University of Engineering Science 8 Technology, Nawabshah, Pakistan under CC BY 4.0 International License. system is adopted, the drift limitations are difficult to be fulfilled, especially with Eurocodes. Eurocodes suggests three limits, namely L1 (0.01h approximately equivalent to the SBC counterpart), L2 (0.0075h), and L3 (0.005h, quite strict limits, used when brittle materials are used for façade) [1][2].

Long span framing configuration is typical in the United States, as generally, the bending effect governs the frames. Since the exterior spatial frame's contribution to vertical loads is smaller than the interior frame, the outer frame contributes more to the lateral loading due to the torsional effects. Such a pattern is typical in Europe and Japan, with limited bay width, which might be due to strict drift limit. The super-structure mass transmits the inertial force to the soil, causing further deformation in the ground, termed as inertial interaction. This phenomenon is vital with increasing mass and is always predominant than the kinematic phenomenon unless it is a very rigid, extended plant or underground structure.

Many researchers dealt with the analysis of structures considering the effect of soil on the structure in 
earthquakes. For example, using Eurocodes, Minasidis et. al. [3] designed 36 planar moment resisting steel frames and examined under the action of 60 near-fault pulse-like records to investigate the effects of SSI on the nonlinear response of 2D steel frames. Mylonakis and Gazetas [4] suggested that considering SSI is beneficial for the response of the overall structure. They showed that the indiscriminate use of ductility concepts and geometric relations is erroneous in assessing seismic performance [4]. Eduardo provided a brief history of SSI by summarising some of the leading developments that paved the way for the state of art known today. Furthermore, as the static foundation stiffnesses are also widely used in engineering analyses and code formulas for SSI effects, therefore, in [5], a brief survey of stationary solutions is provided. Based on dimensional response analysis, Karavasilis et. al. [6] developed a procedure to estimate the maximum inelastic roof displacement and interstory drift ratio and the height of regular multi-story steel frames subjected to pulse-like ground motions. Farouk et. al. [7] modelled 2-bay frames with different rigidities using a geotechnical finite-element program to examine the effect of the frames' rigidity on the contact stress and the differential settlement.

\section{Considered Cases}

Previously, the authors have studied short-span low and mid-rise steel frames to investigate the SSI for loose granular soil using Saudi Building Code (SBC) [8]. To explore the SSI for long-span frames using SBC and Eurocodes, a nine-story square office building measuring $45.75 \mathrm{~m} \times 45.75 \mathrm{~m}$ is adopted in this study. The building's typical floor plan with the indication of perimeter and spatial frames is shown in Figure 1, whereas the elevation in Figure 2. The external columns are denoted as col1 and the inner columns as col2 and col3. The columns are designed considering five blocks. The ground floor is $5.49 \mathrm{~m}$ in height. The height of $3.96 \mathrm{~m}$ is allocated to the rest of the stories with a total height of $37.17 \mathrm{~m}$.

For design purposes, the building is first considered to be composed of moment-resisting frames as the lateral load resisting system along the perimeter (perimeter configuration). Then, it is considered as a spatial system (external and internal one). The three frame configurations, using two ductility classes (DCH and DCM) of Eurocode and special moment-resisting frame of SBC with and without SSI create a total of 18 cases (nine cases with SSI termed as SSI and nine without SSI termed as NSSI (see Table 1).

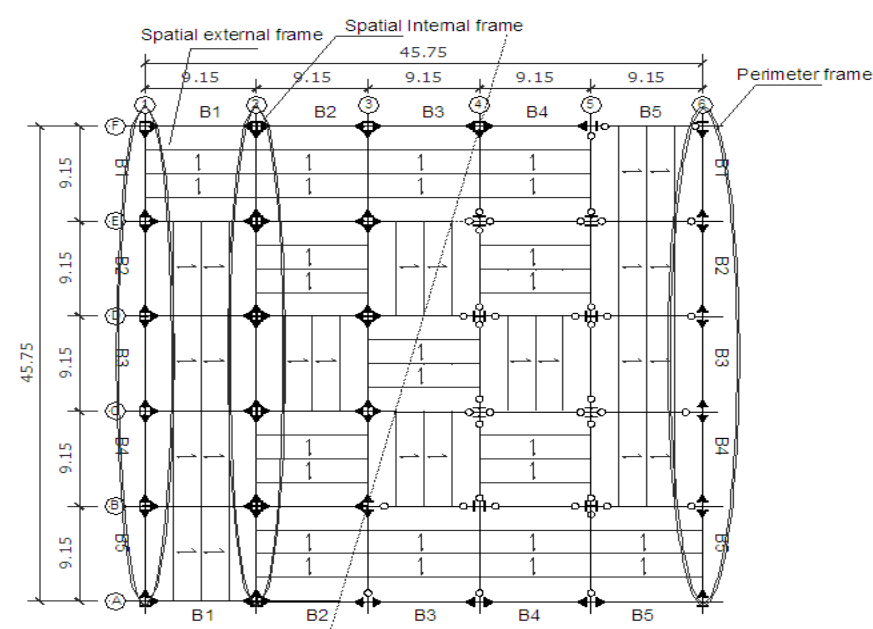

Fig. 1: Typical floor plan using spatial and perimeter MRFs configurations (dimensions are in meter)

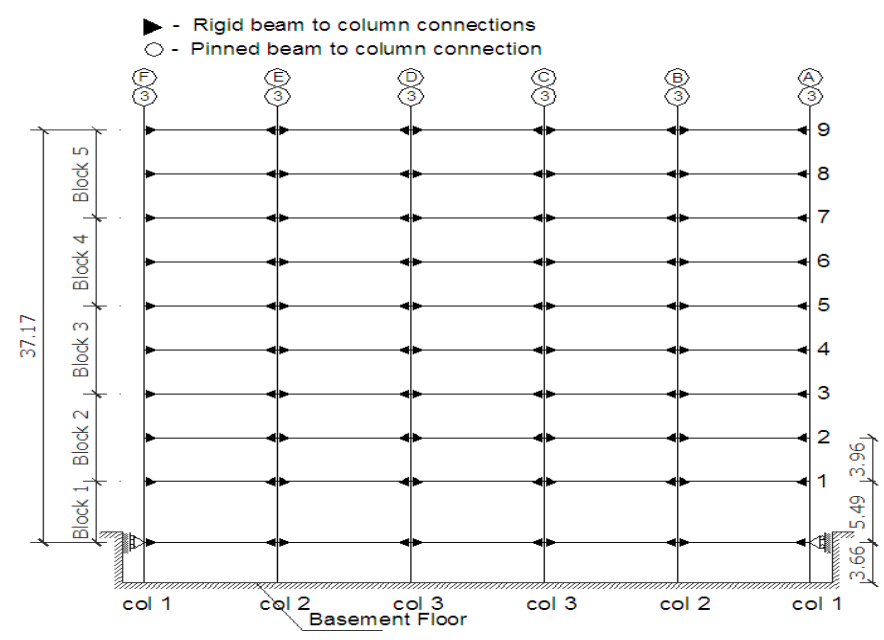

Fig. 2: Frame elevation (dimensions are in meter))

In this research, a flexible foundation effect is considered to check the influence of SSI on momentresisting frame performance. Based on FEMA 356 [10], formulations for the spring constraints of the ground surface are used. The values of static stiffness for translation and rotations are shown in Table 3.

Madinah region of Saudi Arabia is an arid region, and the chance of change in soil properties due to variation in groundwater table is infrequent. Geotech-

\begin{tabular}{|l|l|l|l|l|l|}
\hline $\begin{array}{l}\text { Case } \\
\text { No. }\end{array}$ & $\begin{array}{l}\text { EC3/ } \\
\text { EC8 }\end{array}$ & $\begin{array}{l}\text { Case } \\
\text { No. }\end{array}$ & $\begin{array}{l}\text { EC3/ } \\
\text { EC8 }\end{array}$ & $\begin{array}{l}\text { Case } \\
\text { No. }\end{array}$ & $\begin{array}{l}\text { With } \\
\text { SBC }\end{array}$ \\
\hline 1 & DCH-P* & 4 & DCM-P & 7 & SMF-P \\
\hline 2 & DCH-ES** & 5 & DCM-ES & 8 & SMF-ES \\
\hline 3 & DCH-IS*** & 6 & DCM-IS & 9 & SMF-IS \\
\hline P $^{*}:$ Perimeter, ES**: External Spatial, IS***: Internal Spatial \\
\hline
\end{tabular}

TABLE 1: Analysed cases (SSI and NSSI) 


\begin{tabular}{|l|l|}
\hline Soil parameter & Values \\
\hline Unified Soil Classification & $\begin{array}{l}\text { Medium Plastic } \\
\text { Clayey Sand }(\mathrm{SC})\end{array}$ \\
\hline Average Unit weight $(\gamma)$ & $17.26 \mathrm{kN} / \mathrm{m}^{3}$ \\
\hline Average friction angle $(\phi)$ & $38 \backslash$ degree \\
\hline Cohesion $(\mathrm{c})$ & $16.67 \mathrm{kPa}$ \\
\hline $\bar{N}$ Up to $9^{-m}$ depth & 73.6 \\
\hline$V_{s}$ & $438.42 \mathrm{~m} / \mathrm{s}[9]$ \\
\hline $\begin{array}{l}\text { Shear Modulus } \\
\left(G_{0}=\rho\left(V_{\text {so }}\right)^{2}\right)\end{array}$ & $338 \mathrm{MPa}$ \\
\hline$\nu$ & 0.25 \\
\hline ASCE Classification & $\mathrm{C}$ \\
\hline SDs & $0.7 \mathrm{~g}$ \\
\hline$G$ at high strains & $280.78 \mathrm{Mpa}$ \\
\hline
\end{tabular}

TABLE 2: Geotechnical properties

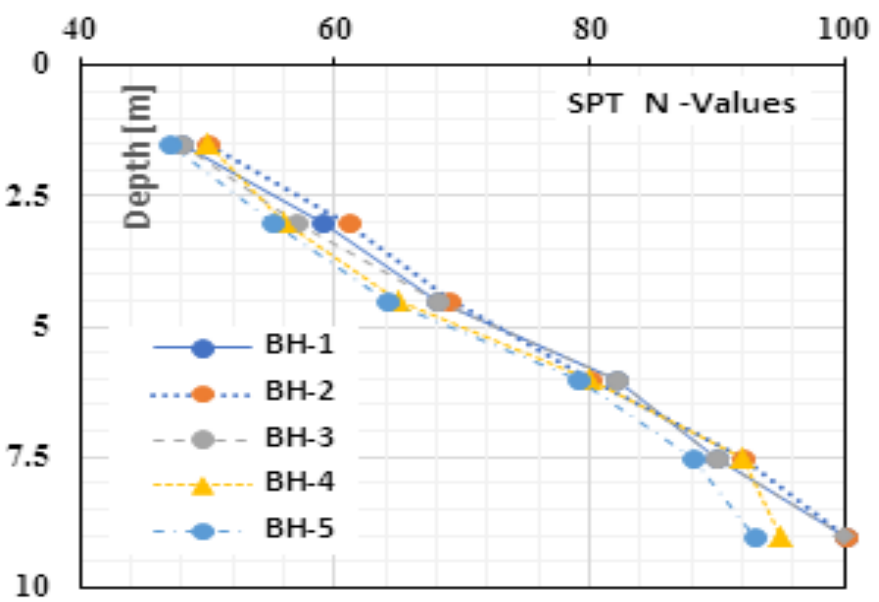

Fig. 3: Standard penetration test results considered for the evaluation of geotechnical Parameters

nical conditions of Madinah are studied in [11]. The soil properties are selected based on the geo-technical investigation report conducted to construct an academic block at the Islamic University of Madinah. Five boreholes $(\mathrm{BH})$ are used in field investigations. The SPT-N values for the site up to expected depth of the influence zone of foundations are shown in Figure 3 [12].

\begin{tabular}{|l|l|l|}
\hline $\begin{array}{l}\text { Displacement \& } \\
\text { Direction }\end{array}$ & Symbol & $\begin{array}{l}\text { Static Stiffness } \\
(\mathbf{N} / \mathbf{m m})\end{array}$ \\
\hline $\begin{array}{l}\text { Horizontal translation } \\
\text { along x }\end{array}$ & $\mathrm{Kx}$ & 1476100 \\
\hline $\begin{array}{l}\text { Horizontal translation } \\
\text { along y }\end{array}$ & $\mathrm{Ky}$ & 1476100 \\
\hline $\begin{array}{l}\text { Vertical translation } \\
\text { along z }\end{array}$ & $\mathrm{Kz}$ & 1759554 \\
\hline Rocking about x & $\mathrm{Kxx}$ & $1.5 \mathrm{E}+12$ \\
\hline Rocking about y & $\mathrm{Kyy}$ & $1.5 \mathrm{E}+12$ \\
\hline Rocking about z & $\mathrm{Kzz}$ & $2.3 \mathrm{E}+12$ \\
\hline
\end{tabular}

TABLE 3: Static stiffness for translation and rotations

\section{Frame Analysis}

Vertical loads are calculated based on EC0 [13] and EC1 [14]. The total structural and non-structural gravity load is $4.6 \mathrm{kN} / \mathrm{m}^{2}$ for the roof and $7.8 \mathrm{kN} / \mathrm{m}^{2}$ for the floor, including an imposed load of $0.4 \mathrm{kN} / \mathrm{m}^{2}$ and $3.0 \mathrm{kN} / \mathrm{m}^{2}$ for the roof and typical floor, respectively. The simple supported secondary beams using S-275 grade steel are spaced at $2.29 \mathrm{~m}$ with an optimized orientation in such a way so that the design is governed equally by strength and deflection [15]. There are HEB-220 for the roof and HEB-280 for the typical floor. The COMFLOR-46 [16] flooring system is used with A252-mesh, $145 \mathrm{~mm}$ thick concrete slab, and $0.9 \mathrm{~mm}$ corrugated steel sheeting acting as diaphragm [17][18].

The perimeter beams and external spatial frames in orthogonal directions are designed in the perspective of seismic conditions. All beams for internal spatial frames in EC3-EC8 [19] are designed for gravity loads, whereas some beams for seismic conditions are as per SBC. Since gravity loading governs beams' design, the ductility class does not influence the dimension of beams. Furthermore, the period is quite high; therefore, the target acceleration does not affect the behaviour factor. Frames are designed as per EC8 with high $(q=6.5)$ and medium ductility $(q=4.0)$, assuming type $C$ soil (dense, cohesive soil, gravels), Important class II $(\gamma I=1.0)$, type 1 spectrum, and $0.25 \mathrm{~g}$ PGA. An equivalent response spectrum for SBC is adopted for the comparison having the same seismic intensity, using importance factor 1.0. Soil type $C$ with $S_{s}$ and $S_{1}$ as $1.07 \mathrm{~g}$ and $0.57 \mathrm{~g}$, respectively. For Madinah Al Munawwarah region, the value of $S S=$ $25.4 / 100 \mathrm{~g}=0.254 \mathrm{~g}$ and $S_{1}=7.3 / 100 \mathrm{~g}=0.073 \mathrm{~g}$ give rise to the values of $S D S$ and $S D 1$ as $0.2 \mathrm{~g}$ and $0.083 \mathrm{~g}$ respectively, and therefore the seismic design category from short and 1-sec period response accelerations is $B$. Nevertheless, the adopted case belongs to a high seismic zone to highlight the influence of $S S I$, and for this reason, according to $S B C$, seismic category $D$ from $S D S(0.713 \mathrm{~g})$ and $S D 1(0.38 \mathrm{~g})$ with the assumed site class is adopted in the present case. This code limits the use of multi-story IMFs in seismic category $D$ up to $10 \mathrm{~m}$ height; therefore, the design considers only $\operatorname{SMF}(\mathrm{R}=7)$ [20-22]. The analysis of the dynamics of linear modal [23] is performed for the seismic design of the frames. The duration of code formulation is $1.3 \mathrm{sec}$, that is approximately $50 \%$ less than the modal response spectrum analysis shown in Figure 4. The lower period permits a conservative design, which means higher design acceleration and more significant inter-story drifts. When using SBC 


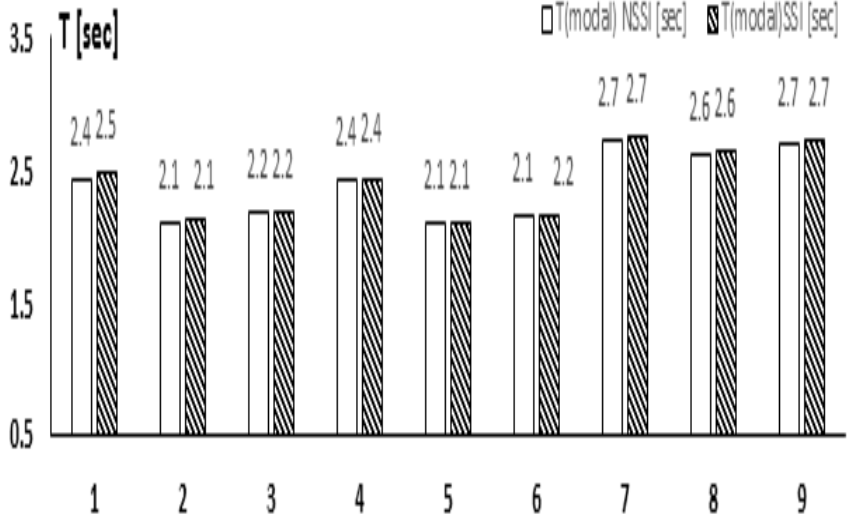

Fig. 4: Fundamental periods for analysed frames with SSI and NSSI

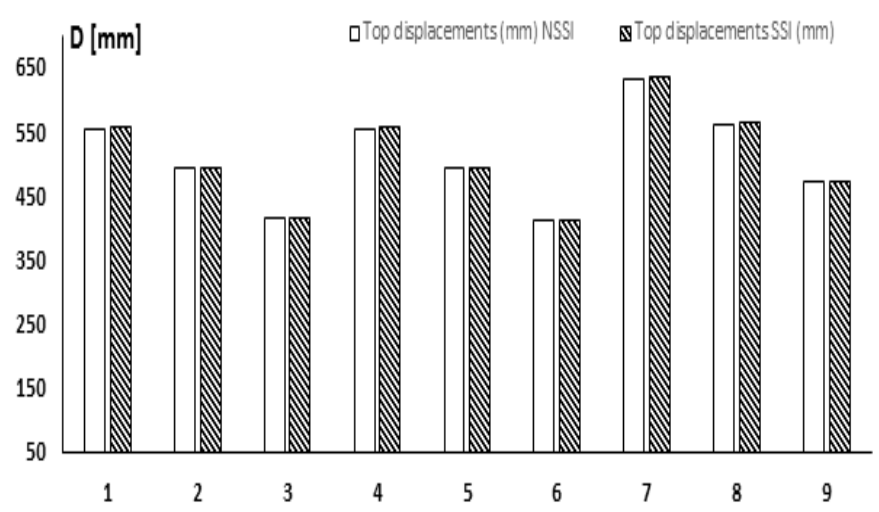

Fig. 5: Top storey displacements for analysed frames with SSI and NSSI

code, the code formulation period is $1.3 \mathrm{sec}$, that is the one obtained by modal analysis. In these conditions, the code suggests that scaling factors for the design forces and drift must be applied.

The top displacements for all the cases are shown in Figure 5. A slight difference can be seen from the obtained top-displacement among the analysed $S S I$ and NSSI cases due to the frames' reduced stiffness when the interaction is considered.

The obtained horizontal shear, vertical and overturning moment reactions for $S S I$ and $N S S I$ for all the analysed cases are compared. Figure 6 shows the node numbering both for the spatial frame and perimeter frame.

Huge differences are observed between the overturning moment in perimeter frames, having ductility class high and medium (see Figure 7, Figure 10, and
Figure 13). Fewer reactions are obtained for spatial moment-resisting frames design using ductility class high and medium using Eurocode and special momentresisting frame using Saudi Building Code (See Figure 8, Figure 9, Figure 11, Figure 12, Figure 14 and Figure $15)$.

\section{Deformability Criteria}

MRFs' high flexibility is the cause of high storey drifts (inter-story deflections), which results in several issues such as undesirable damage to the facade and other non-structural elements that can affect the structural elements as well. Specific components, such as facade elements and columns, are sized for vertical loads. However, their details must also be checked to confirm that they can withstand the deflections imposed on them during the design earthquake. The most common issue with the flexibility of moment frames, particularly in tall buildings, is the design's governing by deflection rather than strength. It might also lead to an inefficient use of material. Furthermore, this can disturb the current building code's capacity design approach to dissipate the energy in a disciplined manner. Damageability criteria must be checked and compared with the code specified limits, principally to limit damage to non-structural elements. SBC 301 sets the maximum drift for ordinary buildings between $1 \%$ and $2.0 \%$ of storey height, depending on the occupancy category. In comparison, Eurocode 8 specifies between $0.5 \%, 0.75 \%$ and $1.0 \%$. The ductility factor " $\mathrm{x}$ " is used by which the deflections obtained from an elastic analysis must be multiplied to allow for plastic deformations. In Eurocode 8, $x$ is taken as the behaviour factor $q$, whereas, in SBC it is considered as a factor $C d$. In Eurocode 8, when the cladding elements are rigidly attached to the structure, the $S L S$ storey drift is limited to $0.5 \%$ of storey height. Still, it is $0.75 \%$ for rigidly attached ductile cladding. When the cladding fixings can accommodate the structural deformations, the drift limit rises to $1 \%$. The Eurocode 8 drift limits are multiplied by 2 , as the elastic spectrum is not reduced by 2 . Instead, limits are increased to compare the $S B C$, where the elastic spectrum is already factored. The drift limit is, therefore, equal to the drift limit 1 of Eurocode. The Eurocode 8 drift limits are very stringent, therefore it affects the approach of capacity design, even after applying the higher limit (0.01h) of EC8. Although the perimeter frames in Case 1 (Figure 16) are designed with drift limit L1 using Eurocode 8. This frame satisfies EC8 limit 1 for $S S I$ and $N S S I$ cases. Some stories meet the drift limit 2 of the EC8, whereas drift limit 3 is not 


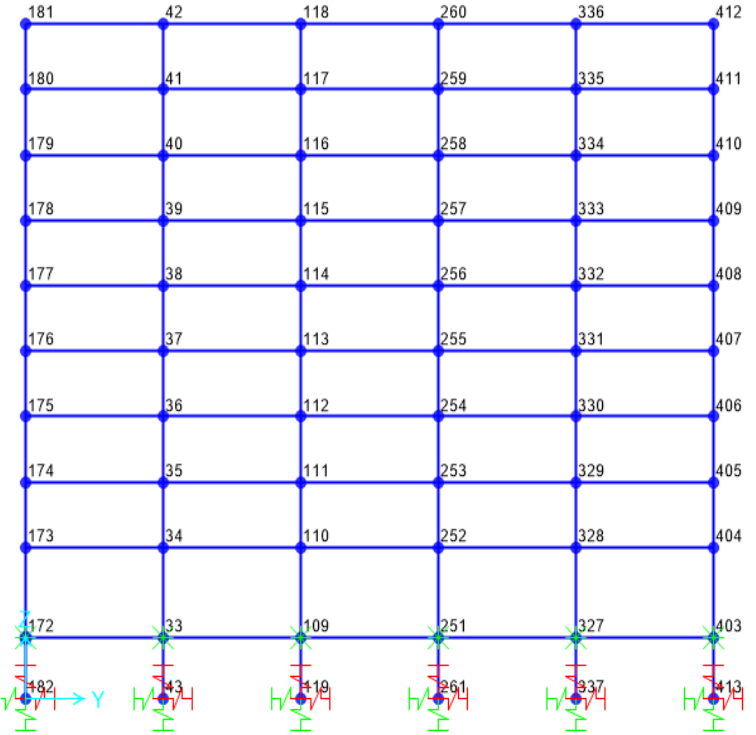

(a)

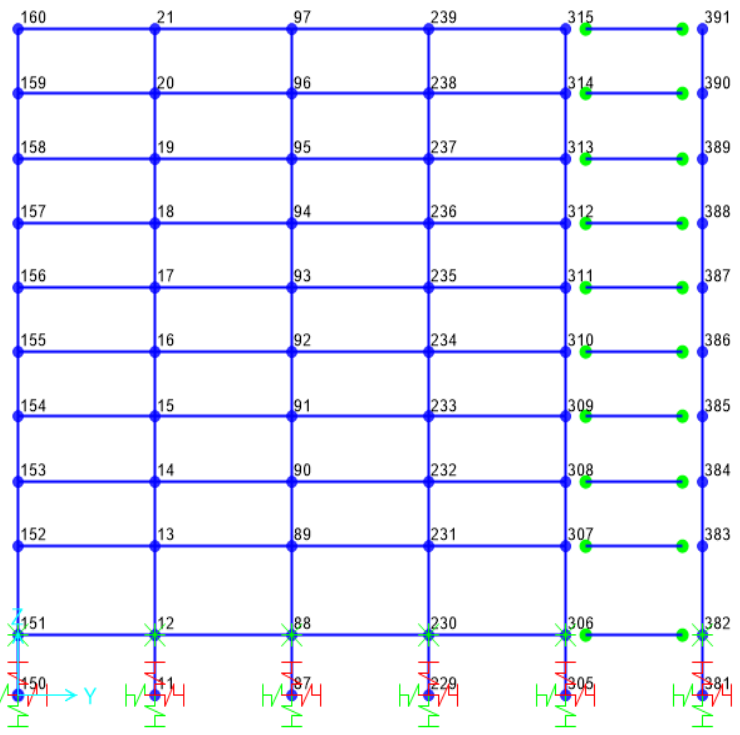

(b)

Fig. 6: Node numbering of the frames, (a) perimeter frame, and (b) spatial frame
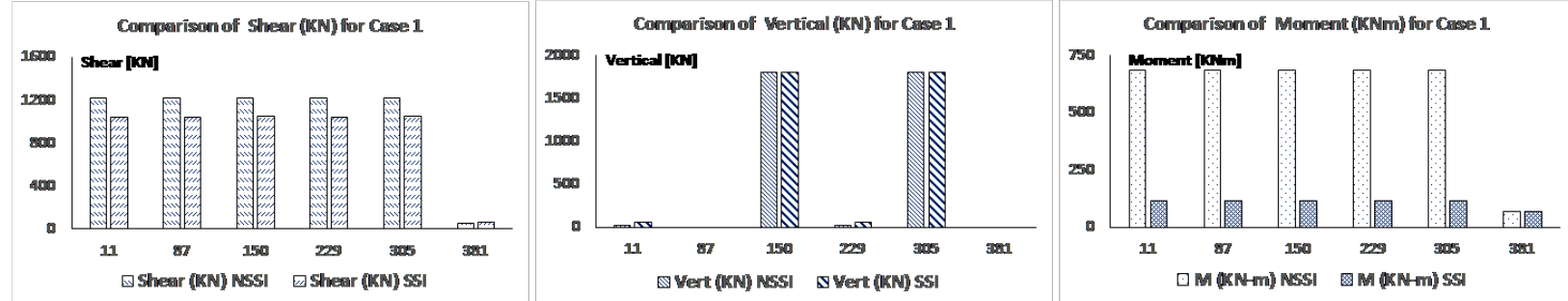

Fig. 7: Case 1: Horizontal shear, vertical shear, and overturning moment reactions for SSI and NSSI of PerimeterDCH designed with Eurocode
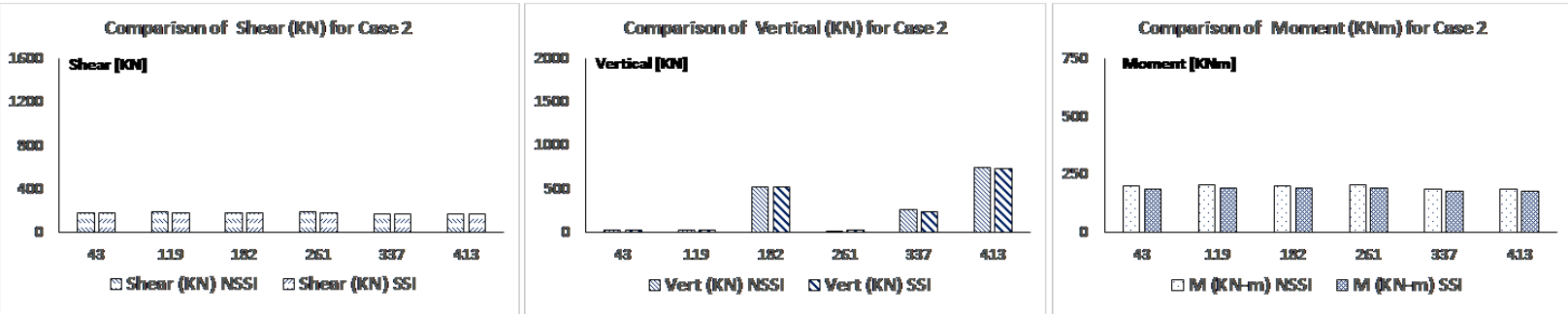

Fig. 8: Case 2: Horizontal shear, vertical shear, and overturning moment reactions for SSI and NSSI of External Spatial-DCH designed with Eurocode
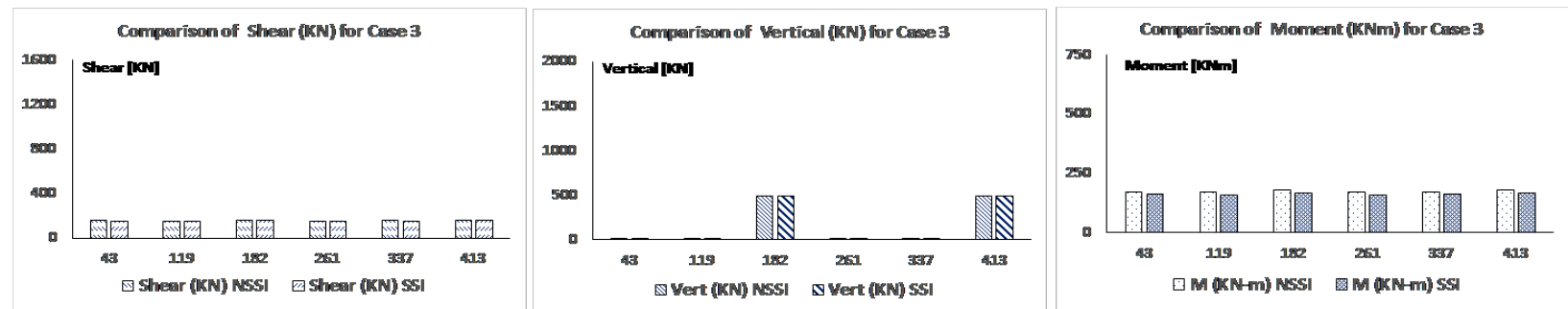

Fig. 9: Case 3: Horizontal shear, vertical shear, and overturning moment reactions for SSI and NSSI of Internal Spatial-DCH designed with Eurocode 

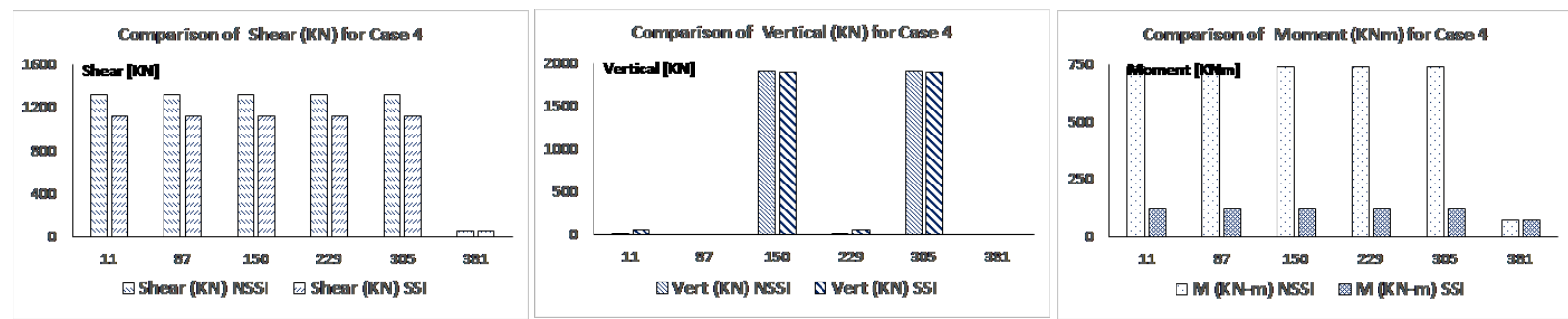

Fig. 10: Case 4: Horizontal shear, vertical shear, and overturning moment reactions for SSI and NSSI of Perimeter-DCM designed with Eurocode
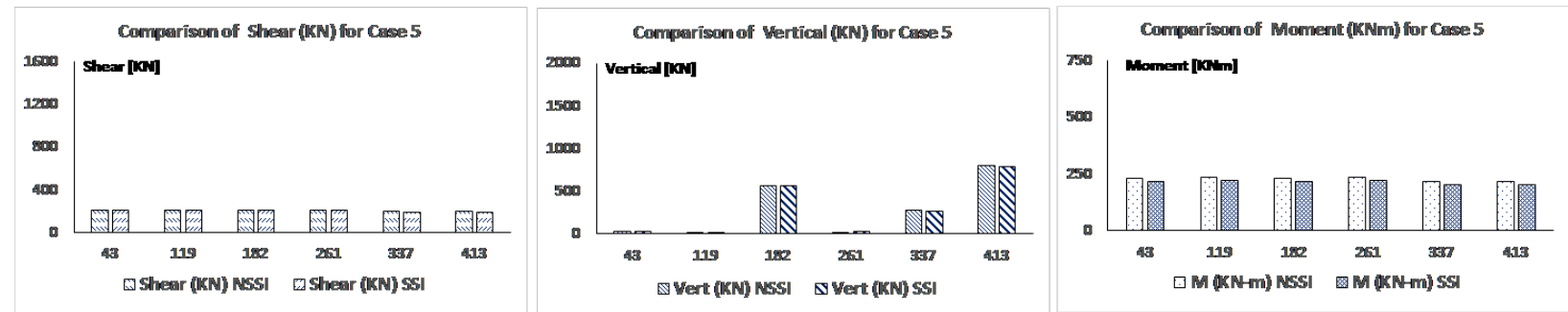

Fig. 11: Case 5: Horizontal shear, vertical shear, and overturning moment reactions for SSI and NSSI of External Spatial-DCM designed with Eurocode
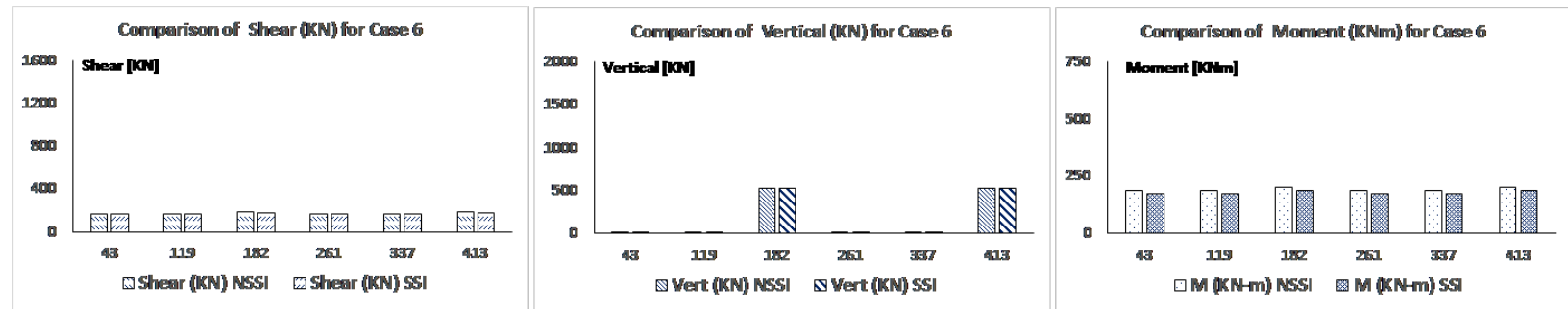

Fig. 12: Case 6: Horizontal shear, vertical shear, and overturning moment reactions for SSI and NSSI of Internal Spatial-DCM designed with Eurocode
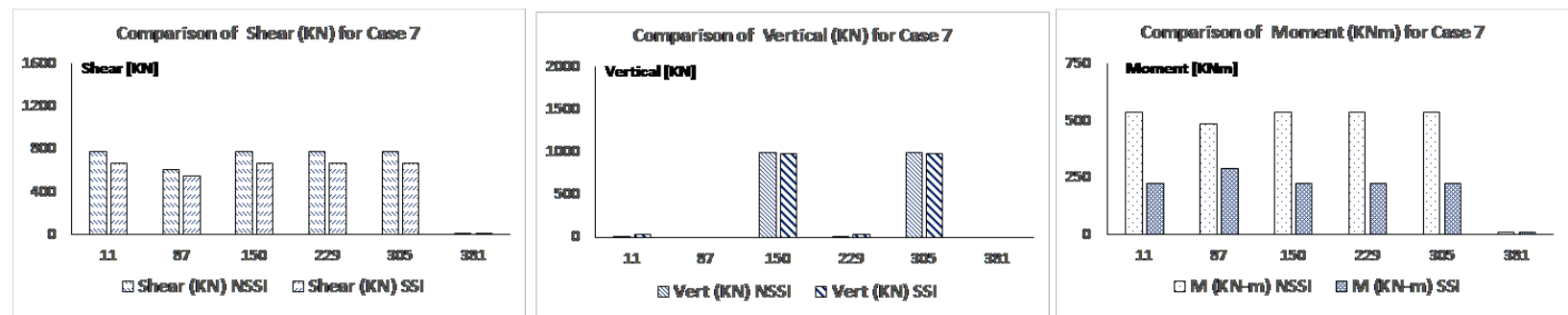

Fig. 13: Case 7: Horizontal shear, vertical shear, and overturning moment reactions for SSI and NSSI of Perimeter-SMF designed with SBC

\begin{tabular}{|l|l|l|}
\hline Drift (Reduce the spectrum) & $\begin{array}{l}\text { Reduce the Spectrum by } 2.0 \\
\text { for I, II importance classes. } \\
\text { Reduce the Spectrum by by } 2.5 \\
\text { for III \&IV importance classes }\end{array}$ & $\begin{array}{l}\text { Reduction factor }=(\mathrm{Cd} / \mathrm{R}=5.5 / 8=1.45) \\
\text { for SMF and }(4.5 / 4=1.125) \text { for IMF }\end{array}$ \\
\hline Drift (Limitation) & $0.005 \mathrm{~h}, 0.0075 \mathrm{~h}$, and $0.01 \mathrm{~h}$ & $0.02 \mathrm{~h}$ \\
\hline
\end{tabular}

TABLE 4: Drift limitations for SBC and Eurocode 8 


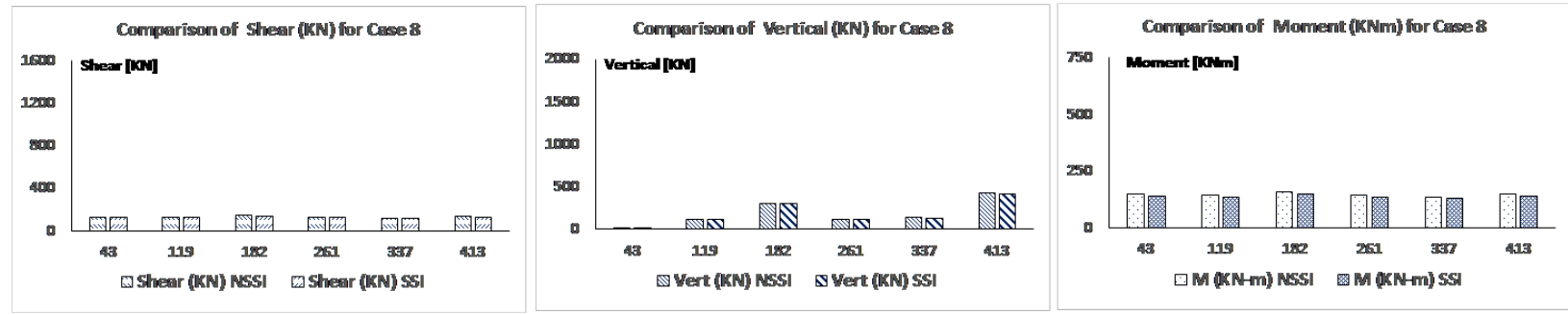

Fig. 14: Case 8: Horizontal shear, vertical shear, and overturning moment reactions for SSI and NSSI of External Spatial-SMF designed with SBC
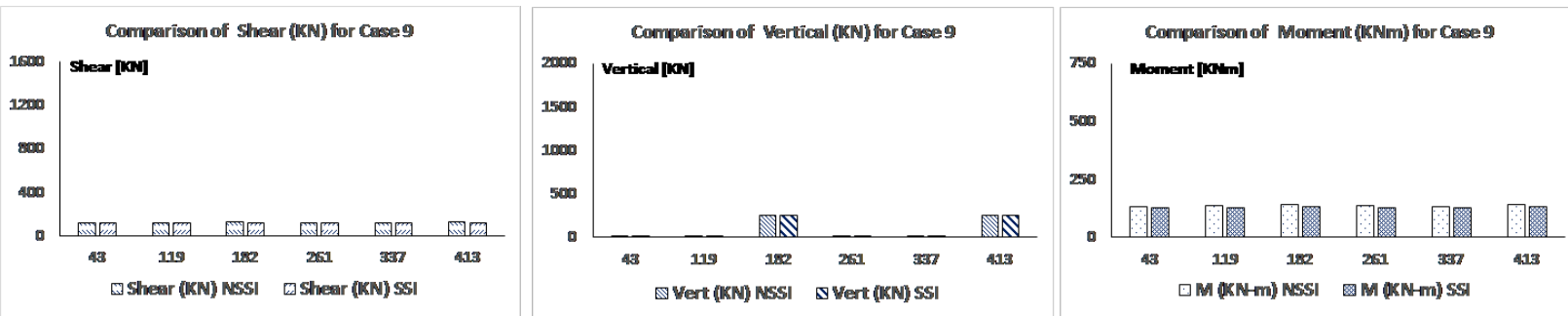

Fig. 15: Case 9: Horizontal shear, vertical shear, and overturning moment reactions for SSI and NSSI of Internal Spatial-SMF designed with SBC

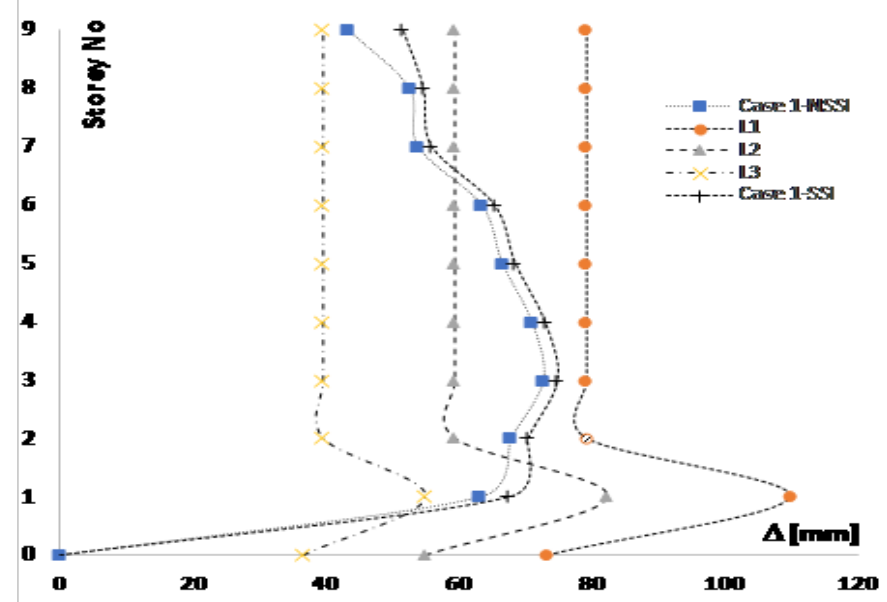

Fig. 16: Case 1: Drift criteria for frames with $S S I$ and NSSI of perimeter-DCH designed with Eurocode

satisfying. External spatial frames design with DCH (case 2, Figure 17) does not satisfy drift limit 2 for a few stories. In contrast, drift limit 3 is not satisfied with any of the storey. A similar result is obtained for case 3 (Figure 18) as well, where the results obtained for the internal spatial frame are shown. While dealing with MRFs' design with the medium ductility class of Eurocode 8, the designed cases (4, 5 and 6) are examined. It is noted that case 4, as shown in Figure 19 (perimeter configuration designed with $D C M$ ) satisfy the relax drift limit $0.01 \mathrm{~h}$ of the code, and this is used in the design also. The other limits are not used as

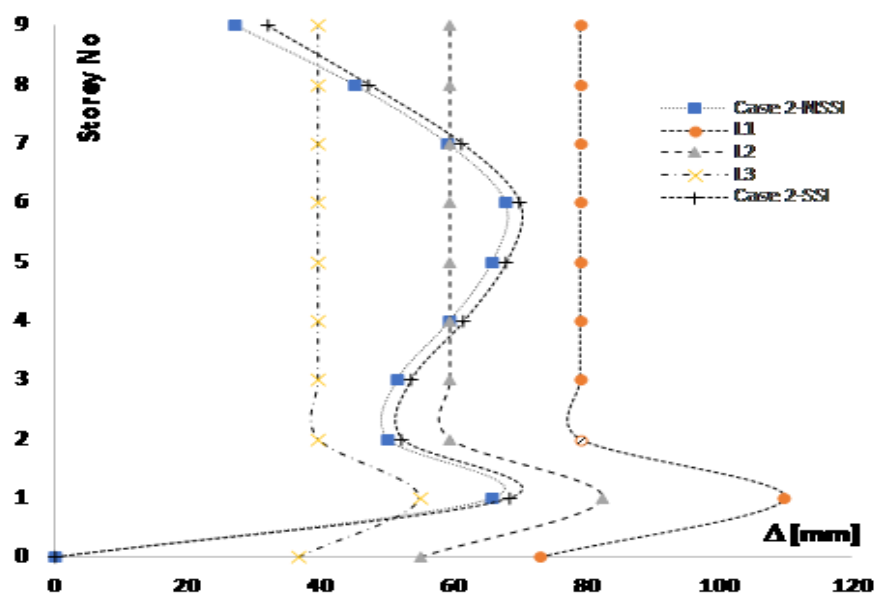

Fig. 17: Case 2: Drift criteria for frames with $S S I$ and NSSI of external spatial-DCH designed with Eurocode

the capacity design will be disturbed by changing the member profiles to improve the frame's stiffness and satisfy the drift limitations. Few stories meet drift limit of $0.0075 \mathrm{~h}$, whereas the strict drift limit $0.005 \mathrm{~h}$ of the code cannot be satisfied by the code with $S S I$ and with NSSI. Quickly satisfaction of drift limit 2 of Eurocode 8 can be seen for spatial frames, especially for the interior one. These are less laterally loaded than gravity loading. That is why few stories in case 5 (Figure 20) do not satisfy the drift limit 2, whereas drift limit 3 cannot be met by most of the stories. A 


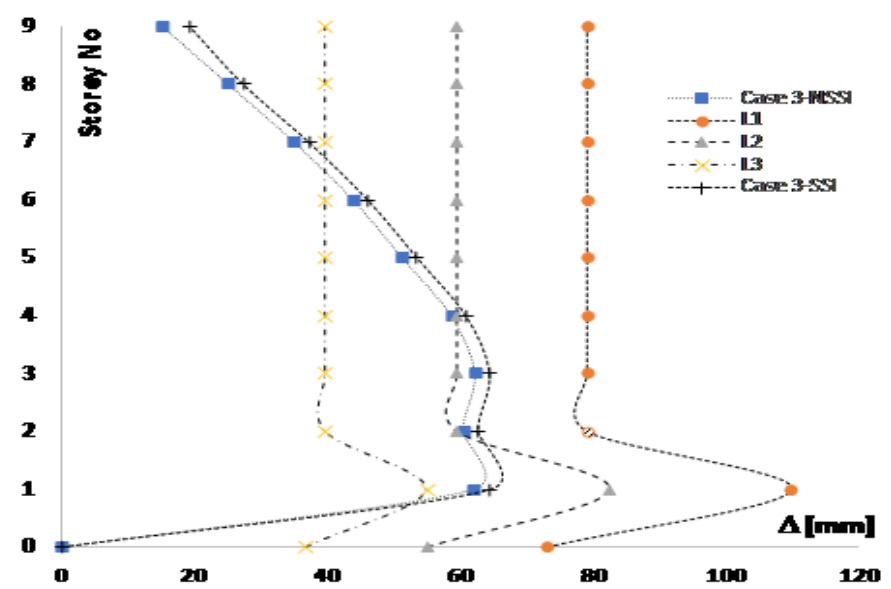

Fig. 18: Case 3: Drift criteria for frames with $S S I$ and NSSI of internal spatial-DCH designed with Eurocode

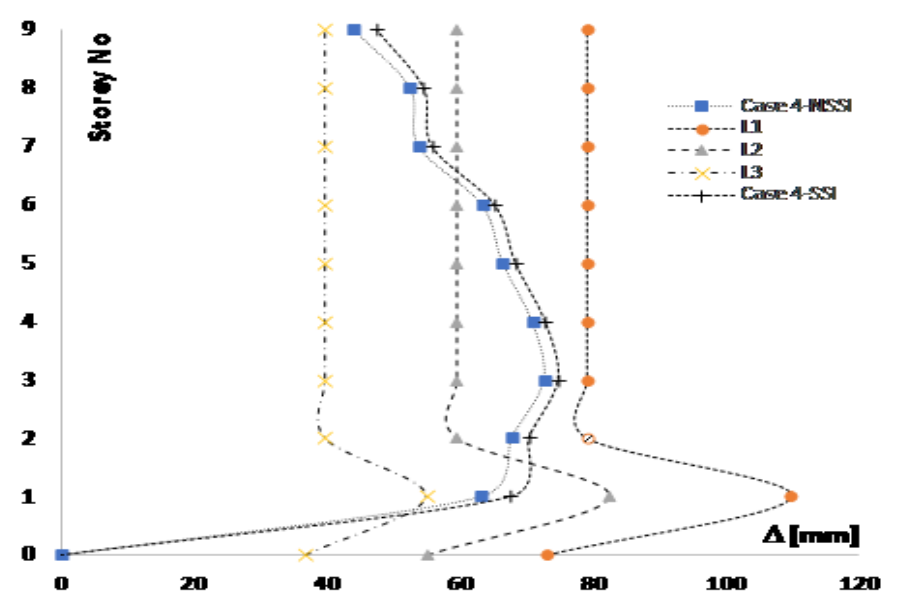

Fig. 19: Case 4: Drift criteria for frames with $S S I$ and NSSI of perimeter-DCM designed with Eurocode

little better result is recorded for case 6 (Figure 21). The last three cases $(7,8$, and 9) shown in Figure 22, Figure 23, and Figure 24, are related to MRFs' design using SBC 301. It is observed that the drift limit (the code suggests only one limit) can be easily satisfied for all the cases except for the perimeter frame where the frame exceeds the drift at some stories with $S S I$.

\section{Conclusion}

- For long-span frames, the stiffness is reduced with the $S S I$ consideration even when the $G$ value is relatively high.

- A slight increase in the fundamental period for all the analysed cases can be noticed for $S S I$ and $N S S I$. The frames with SSI have high fundamental periods as compared to their counterparts.

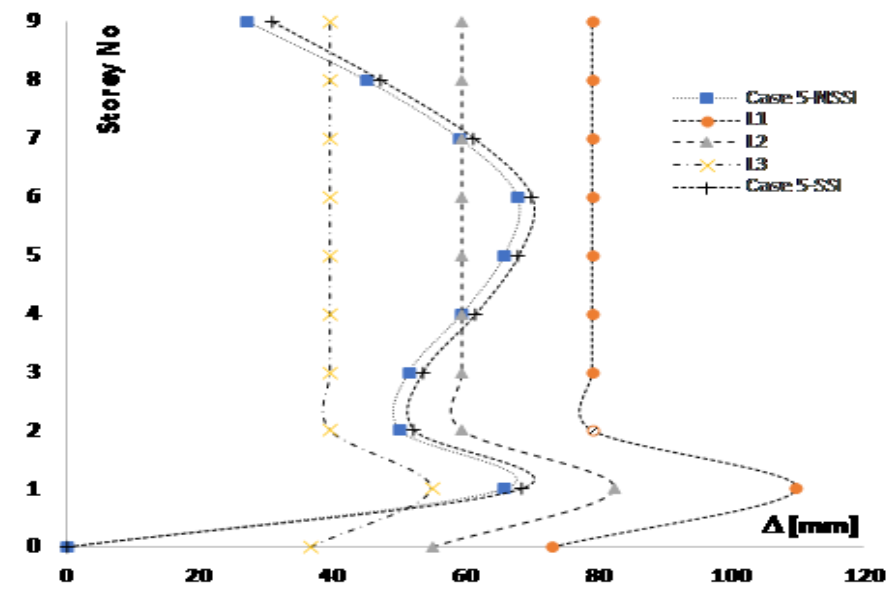

Fig. 20: Case 5: Drift criteria for frames with $S S I$ and NSSI of external spatial-DCM designed with Eurocode

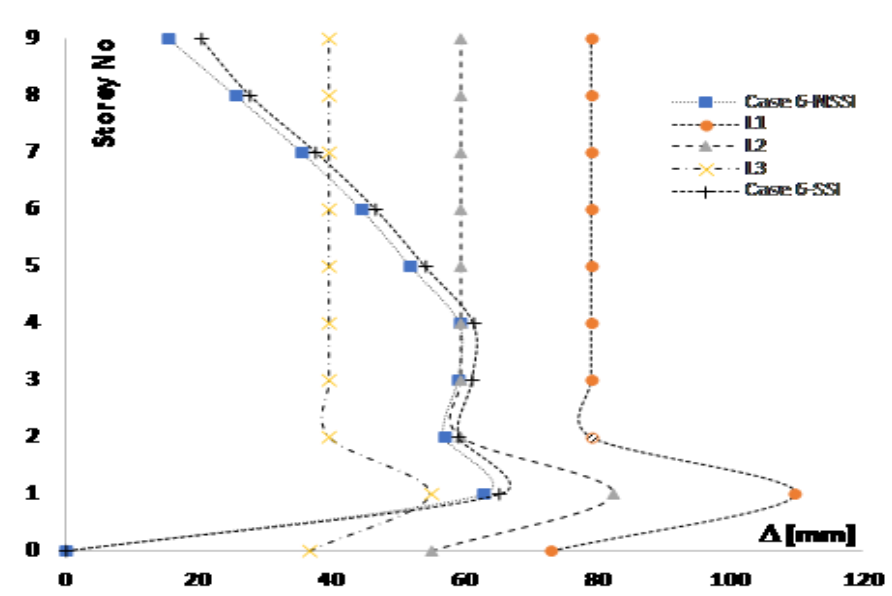

Fig. 21: Case 6: Drift criteria for frames with $S S I$ and NSSI of internal spatial-DCM designed with Eurocode

- The top displacements are high for the frames with the $S S I$

- The inter-story drifts also increase with the consideration, which is alarming for long span or deformable frames.

- Therefore, with the SSI's consideration, the frame's stiffness reduces, and accordingly, the fundamental period and the inter-story drift increases.

- Concerning the comparison codes, it is evident that although frames are designed for limit 1 of Eurocode; nevertheless, the increase in the drifts are still in the range with $S S I$ consideration. However, the other two drift limits must be focused on those cases, and it will be challenging 


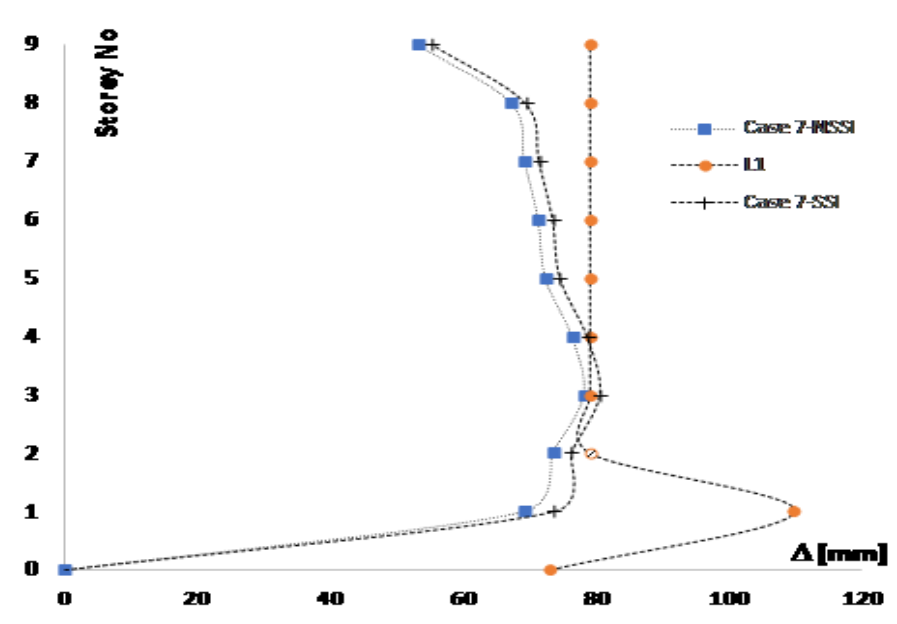

Fig. 22: Case 7: Drift criteria for frames with SSI and $N S S I$ of perimeter-SMF designed with SBC

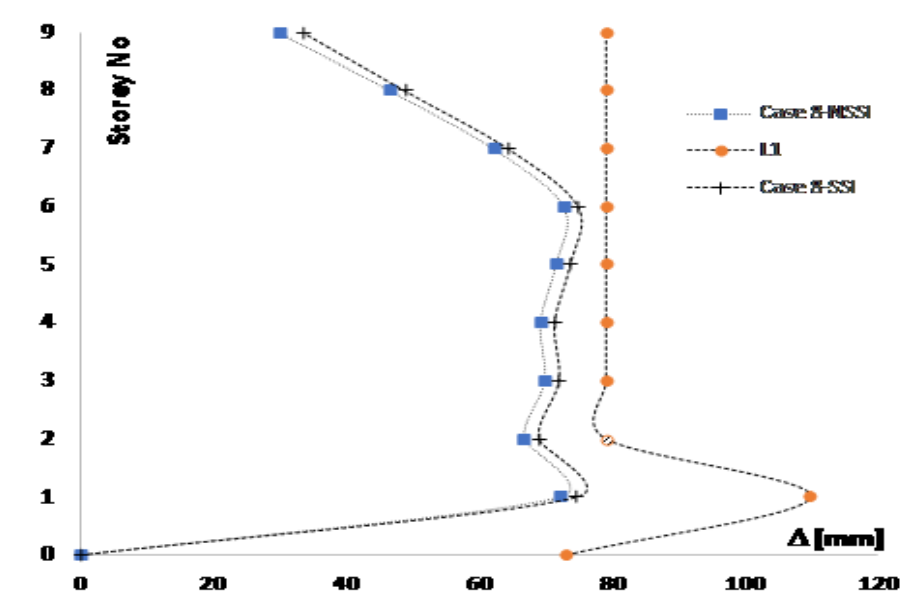

Fig. 23: Case 8: Drift criteria for frames with $S S I$ and $N S S I$ of external spatial-SMF designed with SBC

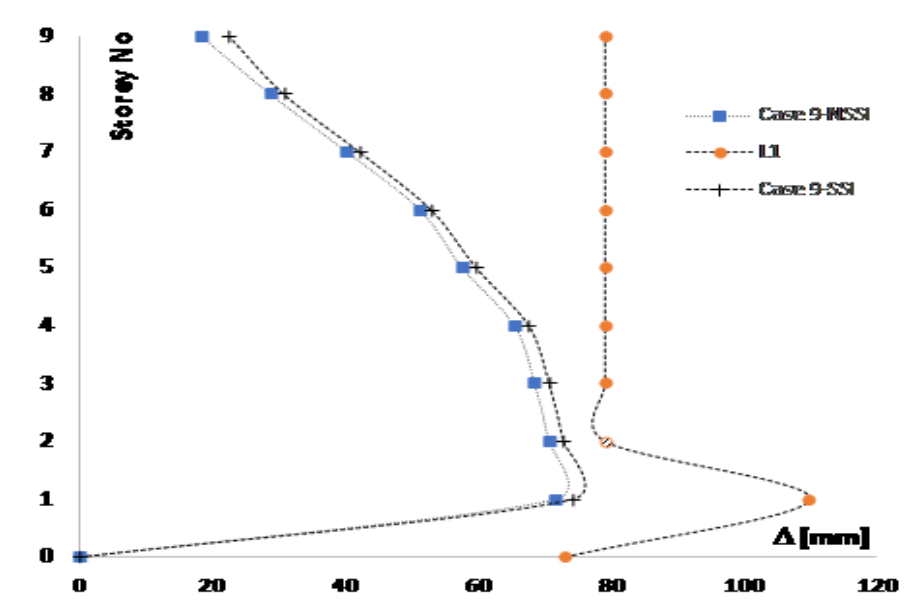

Fig. 24: Case 9: Drift criteria for frames with SSI and NSSI of internal spatial-SMF designed with SBC to satisfy the design criteria when considering $S S I$. The SBC code drift limit is quite acceptable, but $S S I$ is regarded as the drift criteria is not satisfying for case 7 (Perimeter-SMF).

- Overall, the frames that are less loaded with seismic excitation than the gravity loading, such as spatial frames, perform well in the SSI cases. However, when SSI is considered, frames with high seismic loading compared to gravity loading, such as perimeter frames, are more affected.

\section{APPENDIX}

\section{Notations}

\begin{tabular}{|l|l|}
\hline SSI & Soil-Structure Interaction \\
\hline NSSI & Non-Soil Structure Interaction \\
\hline MRFs & Moment Resisting Frames \\
\hline FEMA & $\begin{array}{l}\text { Federal Emergency } \\
\text { Management Agency }\end{array}$ \\
\hline DCM & Ductility Class High \\
\hline SBC & Ductility Class Medium \\
\hline SMF & $\begin{array}{l}\text { Special Moment } \\
\text { Resisting Frame }\end{array}$ \\
\hline EC0 & Eurocode 0 \\
\hline EC1 & Eurocode 1 \\
\hline$q$ & Behaviour Factor \\
\hline$\nu$ & Poisson's Ratio \\
\hline$G$ & $\begin{array}{l}\text { Avear Modulus } \\
\text { Penetration resistance }\end{array}$ \\
\hline $\bar{N}$ & $\begin{array}{l}\text { A short period (0.2 sec) } \\
\text { spectral acceleration }\end{array}$ \\
\hline$S_{s}$ & $\begin{array}{l}\text { Long-period (1 sec) } \\
\text { spectral acceleration }\end{array}$ \\
\hline$S_{1}$ & $\begin{array}{l}\text { Spectral response acceleration } \\
\text { at short periods }\end{array}$ \\
\hline$S_{D S}$ & $\begin{array}{l}\text { Spectral response acceleration } \\
\text { parameter at 1 second }\end{array}$ \\
\hline$S_{D 1}$ & Shear wave velocity \\
\hline$V_{s}$ & $\begin{array}{l}\text { L1 (0.01h, equivalent to the } \\
\text { SBC counterpart) }\end{array}$ \\
\hline Drift limit & L2 (0.0075h) and \\
\hline Drift limit 2 & $\begin{array}{l}\text { L3 (0.005h, structures with } \\
\text { brittle cladding materials })\end{array}$ \\
\hline Drift limit & Interstorey height \\
\hline $\mathrm{h}$ & \\
\hline
\end{tabular}

\section{Acknowledgement}

The authors positively acknowledge the financial support of the Deanship of Research at the Islamic University of Madinah under project No 83/40.

\section{References}

[1] Eurocode Cen., "Eurocode 8: Design Of Structures For Earthquake Resistance-Part 1: General Rules, Seismic Actions and Rules for Buildings (EN 1998-1: 2004)," Eur. Comm. Norm. Brussels, Pages 510, 2004. 
[2] SBC 2007, "Saudi Building Code," 2020. https://www.sbc.gov.sa/En/Pages/default.aspx (accessed Dec. 29, 2020). Structural_Loading and Forces SBC 301. Pages 271, 2020.

[3] G. Minasidis, G. D. Hatzigeorgiou, and D. E. Beskos, "SSI in Steel Frames Subjected to Near-Fault Earthquakes," Soil Dyn. Earthq. Eng, Vol. 66, Pages 56-68, 2014.

[4] G. Mylonakis and G. Gazetas, "Seismic Soil-Structure Interaction: Beneficial Or Detrimental?," J. Earthq. Eng., Vol. 4, no3, Pages 277-301, 2000.

[5] E. Kausel, "Early History Of Soil-Structure Interaction," Soil Dyn. Earthq. Eng., Vol. 30 no 9, Pages 822-832, 2010.

[6] T. L. Karavasilis, N. Makris, N. Bazeos, and D. E. Beskos, "Dimensional Response Analysis of Multistory Regular Steel MRF Subjected to Pulselike Earthquake Ground Motions," J. Struct. Eng., Vol. 136 no 8, Pages 12. 2010.

[7] H. Farouk and M. Farouk, "Soil, Foundation, and Superstructure Interaction for Plane Two-Bay Frames," Int. J. Geomech., Vol. 16, no 1, Pages 11. 2016.

[8] M. T. Naqash, Q. U. Farooq, and O. Harireche, "Seismic Evaluation of Steel Moment Resisting Frames (MRFs)-Supported by Loose Granular Soil," Open J. Earthq. Res., Vol. 8 no 2, Pages 15. 2019.

[9] Y. Ohsaki and R. Iwasaki, "On Dynamic Shear Moduli and Poisson's Ratios of Soil Deposits," Soils Found., Vol.13, no 4, Pages 61-73. 1973.

[10] FEMA 356, "FEMA 356 Prestandard," US Fed. Emerg. Manag. Agency, 2000.

[11] ASTM D422, "Standard Test Method for Particle-Size Analysis of Soils," Astm, 2007.

[12] D. ASTM, "Standard Practice for Classification of Soils and Soil-Aggregate Mixtures for," Current, 1993.

[13] E. Standard, "Eurocode 0 - Basis of Structural Design," Eurocode 0, 2002.

[14] Eurocode 1 - Actions on structures," Bauingenieur, 2011

[15] J. Farkas and K. Jármai, Optimum design of steel structures. 2013. Engineering Structures and Technologies, 6:1, 42, Vol. 1, Pages 292. 2013.

[16] "Composite Floor Decks, Composite Decking - $\quad$ Tata Steel." https://www.tatasteelconstruction.com/en_GB/Products /structural-buildings-and-bridges/Composite-floor-deck (accessed Nov. 21, 2020).

[17] M. T. Naqash, G. De Matteis, and A. De Luca, "Critical Overview On The Seismic Design Of Steel Moment," in 45th Convention of IEP, Karachi Pakistan, pp. 1-15. 2012.

[18] M. T. Naqash, "A Study on the Damageability Issue in the Design of Steel Moment Resisting Frames," Am. J. Civ. Struct. Eng., Vol.1 no 4 Pages 96-103. 2014.

[19] BS EN 1993-1-1, "BS EN 1993-1-1:2005+A1:2014 Eurocode 3 - Design of Steel Structures - Part 1-1: General rules and rules for buildings," Eurocode 3. 2014.

[20] M. T. Naqash, G. De Matteis, and A. De Luca, "Seismic Design Of Steel Moment Resisting Frames (MRFS)- European Versus American Practice," Ned Univ. J. Res. Vol: Thematic Issue on Earthquakes Pages 45-59. 2012.

[21] M. T. Naqash, G. De Matteis, and A. De Luca, "Effects of Capacity Design Rules on Seismic Performance of Steel Moment Resisting Frames," 15 WCEE Lisboa, Pages 10. 2012.

[22] M. T. Naqash and A. Alluqmani, "Codal Requirements Using Capacity Design Philosophy, and Their Applications in the Design of Steel Structures in Seismic Zones," Open J. Earthq. Res., Vol. 7 no 2, Pages, 88-107. 2018,

[23] "Structural Software for Analysis and Design - SAP2000." https://www.csiamerica.com/products/sap2000 (accessed Nov. 21, 2020). 